\title{
WHAT ARE WE TELLING THE PARENTS OF EXTREMELY PRETERM BABIES?
}

Rosemarie Anne BOLAND ${ }^{1,2,3}$ Peter Graham DAVIS ${ }^{2,4}$, Jennifer Anne

DAWSON $^{1,2,4}$, and Lex William DOYLE. ${ }^{1,2,4}$

${ }^{1}$ Murdoch Childrens Research Institute, 50 Flemington Road, Parkville, Victoria, Australia, 3052.

${ }^{2}$ Department of Obstetrics and Gynecology, University of Melbourne, $7^{\text {th }}$ Floor, Royal

Women's Hospital, 20 Flemington Road, Parkville, Victoria, Australia, 3052.

${ }^{3}$ Paediatric Infant Perinatal Emergency Retrieval, Royal Children's Hospital, 50

Flemington Road, Parkville, Victoria, Australia, 3052.

${ }^{4}$ Department of Newborn Research, Royal Women's Hospital, Locked Bag 300, Parkville, Victoria, Australia, 3052.

\section{Author positions and institutional affiliations}

Dr Rosemarie Anne BOLAND

Postdoctoral Research Fellow

Murdoch Childrens Research Institute

50 Flemington Road,

Parkville. VIC 3052

T) 61383453781

F 61383453789

E| rose.boland@mcri.edu.au

Honorary Clinical Senior Lecturer

Department of Obstetrics and Gynaecology,

University of Melbourne,

This is the author manuscript accepted for publication and has undergone full peer review but has not been through the copyediting, typesetting, pagination and proofreading process, which may lead to differences between this version and the Version of Record. Please cite this article as doi: 10.1111/ajo.12448

This article is protected by copyright. All rights reserved 
$7^{\text {th }}$ Floor, Royal Women's Hospital

Locked Bag 300,

Parkville. Victoria. 3052

$\mathrm{T}$ | 61383453781

E | rosemarie.boland@unimelb.edu.au

Nurse Educator

Paediatric Infant Perinatal Emergency Retrieval (PIPER)

Royal Children's Hospital

50 Flemington Road,

Parkville. VIC 3052

T | 61393459021

E| rose.boland@netsvic.org.au

\section{Professor Peter Graham DAVIS}

Professor of Neonatal Medicine

Department of Obstetrics and Gynaecology,

University of Melbourne,

$7^{\text {th }}$ Floor, Royal Women's Hospital

Locked Bag 300,

Parkville. Victoria. 3052

T| 61383453768

E|pgd@unimelb.edu.au

Professor/Director, Department of Newborn Research,

Royal Women's Hospital

Locked Bag 300

Parkville. VIC 3052

Neonatal Research

Murdoch Childrens Research Institute

50 Flemington Road,

Parkville. VIC 3052

\section{Dr Jennifer Anne DAWSON}

This article is protected by copyright. All rights reserved 
Postdoctoral Research Fellow

Department of Obstetrics and Gynaecology,

University of Melbourne,

$7^{\text {th }}$ Floor, Royal Women's Hospital

Locked Bag 300,

Parkville. Victoria. 3052

T| 61383453791

E| jennifer.dawson@thewomens.org.au

Deputy Director: Department of Newborn Research,

Royal Women's Hospital

Locked Bag 300

Parkville. VIC 3052

Neonatal Research

Murdoch Childrens Research Institute

50 Flemington Road,

Parkville. VIC 3052

\section{Professor Lex William DOYLE}

Professor of Neonatal Paediatrics

Department of Obstetrics and Gynaecology,

University of Melbourne,

$7^{\text {th }}$ Floor, Royal Women's Hospital

Locked Bag 300,

Parkville. Victoria. 3052

$\mathrm{T} \mid 61383453716$

El $\underline{1 w d @ u n i m e l b . e d u . a u ~}$

Professor of Neonatal Paediatrics

Department of Paediatrics

Murdoch Childrens Research Institute

50 Flemington Road,

Parkville. VIC 3052

This article is protected by copyright. All rights reserved 
Professor of Neonatal Paediatrics

Royal Women's Hospital

Locked Bag 300

Parkville. VIC 3052

\section{Corresponding author}

Dr Rosemarie Anne Boland

Postdoctoral Research Fellow

Murdoch Childrens Research Institute

Level 7, Royal Women's Hospital

Locked Bag 300,

Parkville, Victoria. 3052 Australia.

E: rose.boland@mcri.edu.au

T: (61) 383453781

\section{Short title:}

What are we telling the parents of EPT babies?

\section{Word Count:}

Abstract: 250 words, Main Text: 3050 words

\section{Acknowledgements}

The authors wish to thank Dr Mary-Ann Davey at the Clinical Council's Unit, Health Service Programs Branch, Victorian Department of Health and Human Services, for providing the denominators for all 24 and 28-week livebirths free of lethal anomalies in Victoria in 2001-2009 and infant mortality data. The authors wish to thank the Victorian Infant Collaborative Study Group (VICS) for allowing access to the neurosensory outcome data for surviving children enrolled in the 1991-1992, 1997 and 2005 VICS cohorts. We express our gratitude to the midwives, nurses, and medical practitioners in Victoria who willingly participated in this research. Special thanks to the Nurse Unit Managers and Medical Directors of the tertiary NICUs, and staff at the Royal Australian College of Obstetricians and Gynaecologists for distributing the survey on our behalf.

This article is protected by copyright. All rights reserved 


\section{Conflict of Interest}

There are no conflicts of interest declared by the authors, real or perceived.

\section{Financial support}

RAB was the recipient of the Felix Meyer Faculty Research Scholarship from the Faculty of Medicine, Dentistry and Health Sciences at the University of Melbourne. Her PhD research was also supported with funding from a National Health and Medical Research Council (NHMRC) Centre for Research Excellence in Newborn Medicine at the Murdoch Childrens Research Institute [ID 1060733]. JAD and PGD are funded by the NHMRC: JAD holds an Early Career Fellowship [ID 1059111]; PGD holds a Practitioner Fellowship [ID 1012686].

\section{Key words:}

Extremely preterm infant, mortality, neurodevelopmental disability, outcomes, counselling.

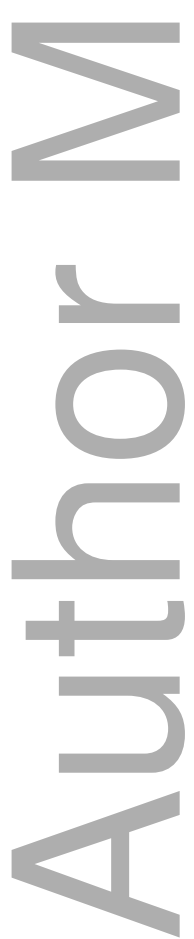

This article is protected by copyright. All rights reserved 


\section{WHAT ARE WE TELLING THE PARENTS OF EXTREMELY PRETERM \\ BABIES?}

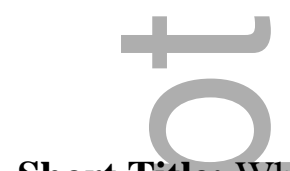

Short Title: What are we telling the parents of EPT babies?

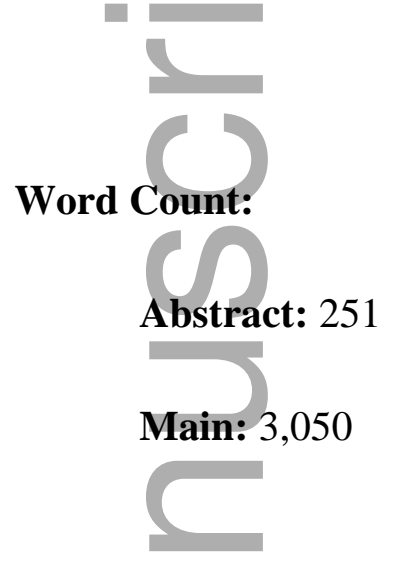

Tables: Two

Figures: FourABSTRACT

\section{Background}

Parent counselling and decision-making regarding the management of preterm labour and birth is influenced by information regarding potential infant outcomes provided by healthcare providers.

Aim

The aim of this study was to determine if perinatal healthcare providers had accurate perceptions of survival and major neurosensory disability rates of very preterm infants born in non-tertiary hospitals ("outborn") and tertiary perinatal centres ("inborn").

\section{Material and Methods}

This article is protected by copyright. All rights reserved 
A web-based survey was distributed to midwives, nurses, obstetricians and neonatologists working in tertiary and non-tertiary maternity hospitals, and the perinatal/neonatal emergency transport services in Victoria, Australia.

\section{Main outcome measures}

Estimates of survival rates at 24 and 28 weeks' gestation were compared with actual survival rates of a population-based cohort of 24 and 28-weeks' gestation infants, born free of lethal anomalies in Victoria in 2001-2009.

Estimates of major neurosensory disability in 24 and 28-week survivors were compared with actual disability rates in 24 and 28-week children born in Victoria averaged over three eras: 1991-1992, 1997 and 2005.

\section{Results}

Response rates varied: $83 \%$ of non-tertiary midwives, $4 \%$ of obstetricians, $55 \%$ of tertiary centre staff and $68 \%$ of transport team staff responded (total of $30 \%$ ). Overall, respondents underestimated survival and overestimated major neurosensory disability rates in both outborn and inborn 24 and 28-week infants. Outborn infants were perceived to have much worse prospects for survival and for survival with major disability compared with inborn peers.

\section{Conclusion}

Many clinicians overestimated rates of adverse outcomes. These clinicians may be misinforming parents about their child's potential for a favorable outcome.

\section{Key words:}

Extremely preterm infant, mortality, neurodevelopmental disability, outcomes, counselling Introduction 
Counselling parents facing the birth of an extremely preterm infant involves a discussion about the risks of death or survival with significant disability. It is imperative that clinicians conducting such discussions provide parents with accurate estimations of these risks. Previous studies have demonstrated that many perinatal healthcare providers have misconceptions regarding outcomes of infants born extremely preterm, underestimating survival rates and overestimating rates of major neurosensory impairment in surviving children. ${ }^{1-5}$ Moreover, clinicians who perceived survival chances to be poor were less likely to transfer in-utero, administer antenatal corticosteroids or to resuscitate the infant. ${ }^{3,6}$

Keeping up-to-date with outcomes for extremely preterm infants is challenging, as wide variations in survival rates and survival without impairment are reported. ${ }^{7,8}$ Such variations have been attributed to differences in physician attitudes and hospital practices regarding provision of perinatal interventions, 9,10 and according to the level of perinatal care available at the hospital. ${ }^{11}$ In Victoria, Australia, infants born extremely preterm (EPT) or extremely low birth weight outside of a tertiary centre ("outborn”) have significantly lower survival rates compared with tertiary centre ("inborn") peers. ${ }^{12,13}$ However, they are also less likely to be offered neonatal intensive care compared with inborn infants. In 2010-2011, only $29 \%$ of outborn 23-24 weeks' gestation livebirths, free or lethal anomalies were admitted to NICU, compared with $71 \%$ of inborn livebirths. ${ }^{14}$ Such disparities indicate that differences in clinical decision-making exist. This led us to question whether decisions to withhold or provide perinatal interventions and parent counselling are based on accurate perceptions of outcome.

The aim of this study was to ascertain if perinatal healthcare providers throughout the state of Victoria, Australia, had accurate perceptions of survival rates and rates of major neurosensory disability for 24 and 28 weeks' gestation outborn and inborn infants.

\section{Methods}

We designed a web-based survey using SurveyMonkey. ${ }^{\text {TM }}$ The Human Research Ethics Committees at all three tertiary perinatal centres in Victoria approved the study (Mercy 
Health [R10/45], Southern Health [10301Q), and The Royal Women's Hospital [QA/Audit, 2010]. Individual consent was implied by voluntary completion of the survey.

Four groups of perinatal healthcare providers were targeted: 1) Senior midwives from nontertiary hospitals with Level 1 or 2 obstetric and neonatal services, 2) general practitioners (GPs), obstetricians and specialist obstetricians from non-tertiary hospitals with Level 1 or 2 obstetric and neonatal services; 3) senior nursing and all medical staff from neonatal intensive care units (NICUs) at perinatal centres, and 4) all nursing and medical staff from the state-wide perinatal (PERS) and neonatal (NETS) emergency transport team.

The survey consisted of ten questions in three parts. Demographic information about the participants' profession and years of perinatal care experience were collected in Part A.

Part B explored perceived chances of survival. Participants were asked to estimate the chance of survival to discharge home following livebirth in a non-tertiary hospital at 24 and at 28 weeks' gestation. A rating scale ranging from $0 \%$ (no chance of survival) to $100 \%$ (100\% chance of survival) in $10 \%$ increments was provided. The questions were repeated for infants born in a tertiary perinatal centre.

Part C explored perceived risks of major neurosensory disability in surviving children. Participants were asked to estimate the chance of major neurosensory disability for a surviving child born in a non-tertiary hospital at 24 or at 28 weeks' gestation and in a tertiary perinatal centre at 24 and 28 weeks. Major neurosensory disability was defined for survey participants as "major problems with thinking, walking, talking and seeing". A scale of 0 (no chance of major disability) to $100 \%$ (all survivors having a major disability) was provided.

The survey was distributed by email between September 2010 and August 2011.

\section{Statistical analysis}

This article is protected by copyright. All rights reserved 
The responses were downloaded into Excel $^{\mathrm{TM}}$ (Version 14.3.4 for MAC, Microsoft, 2010, Redmond, USA), and analysed using STATA/ICTM (Version 13.1 for MAC, 2014, StataCorp, Texas, USA). For each question regarding estimations of survival and major neurosensory disability risk, the mean, standard deviation (SD) and 95\% confidence intervals (CI) for each participant group were compared. Differences between the groups for each question regarding survival and major neurosensory disability were analysed using one-way ANOVA.

The participants' estimates of survival for 24 and 28 -week infants were compared with survival data obtained from a population-based cohort of all livebirths born free of lethal anomalies in Victoria in 2001-2009. The Clinical Council's Unit, Victorian Department of Health and Human Services provided these data to the investigators after ethics was approved [RR13-10].

The participants' estimates of major neurosensory disability were compared with the true rates of disability for infants born in Victoria averaged over three eras: 1991-1992, 1997 and 2005. These data were obtained from the Victorian Infant Collaborative Study Group (VICS), who had published the neurosensory outcomes at two years of corrected age for children $<28$ weeks' gestation or $<1000 \mathrm{~g}$ birth weight in Victoria. ${ }^{15,16}$

\section{RESULTS}

The survey was sent to 1,143 perinatal healthcare providers. The response rate was $30 \%$ $(n=339)$, however response rates varied: 91 (83\%) non-tertiary midwives, $28(4 \%)$ nontertiary obstetricians, $185(55 \%)$ tertiary centre staff and $34(68 \%)$ transport team staff completed the survey (Table 1). The Royal Australian and New Zealand College of Obstetricians and Gynaecologists (RANZCOG) distributed the survey to all RANZCOG practitioners, including gynaecologists, who were ineligible to participate. Not withstanding, the response rate from non-tertiary obstetric staff was poor. Excluding the 650 RANZCOG practitioners, the response rate was $63 \%$.

This article is protected by copyright. All rights reserved 
The participants were experienced practitioners, reporting a median of 15 years working in perinatal care (interquartile range [IQR] 5 to 23 years). Despite their years of experience, respondents from non-tertiary hospitals had attended very few livebirths <28 weeks' gestation in the past five years (Table 2). The highest number of livebirths attended by a medical practitioner from a non-tertiary hospital was five. In contrast, medical staff from the tertiary centres had attended a median of 30 births (IQR 15,60) and medical staff at PERS/NETS had attended a median of 38 (IQR 10, 50).

\section{Perceptions of survival if outborn livebirth at 24 weeks' gestation}

In 2001-2009 there were 324 livebirths free of lethal anomalies at 24 weeks' gestation. Forty-nine infants (15\%) were outborn, of whom 18 (37\%) were alive at one year (18/36 admitted to NICU).

Most participants underestimated the chance of survival following outborn birth at 24 weeks' gestation (Figure 1A). Non-tertiary midwives and PERS/NETS transport teams' estimates of survival were closest to the true survival rate. Non-tertiary GP/obstetricians and tertiary centre medical staff had substantially lower estimates of survival (means of $22 \%$ [SD 16.6] and 25\% [SD 16.9] respectively. There were statistically significant differences in the perceptions of survival chances between the four participant groups overall $(\mathrm{p}=0.018)$.

\section{Perceptions of survival if inborn livebirth at 24 weeks' gestation}

Of the 324 livebirths at 24 weeks' gestation, 275 (85\%) were born in a tertiary perinatal centre. At one year, 175 (64\%) were alive (175/256 admitted to NICU).

Many practitioners underestimated the chance of survival to discharge for an inborn 24week infant (Figure 1B). Overall, the GPs and obstetricians from non-tertiary hospitals had the least accurate perceptions of survival. The estimates of non-tertiary midwives and 
PERS/NETS staff were closest to the actual rate. The differences in perceptions of survival between the four participant groups were statistically significant $(p=0.004)$.

\section{Perceptions of survival if outborn livebirth at 28 weeks' gestation}

In 2001-2009 there were 765 livebirths at 28 weeks' gestation. Of these, 118 (15\%) were outborn, of whom 113 (96\%) were alive at one year (113/117 admitted to NICU).

The majority of respondents underestimated the chance of survival to discharge for an outborn 28-week infant (Figure 2C). Non-tertiary midwives were the least pessimistic, while tertiary centre staff were the most pessimistic. Only $8 \%$ of tertiary medical staff estimated survival rates within $10 \%$ of the true rate. There were statistically significant differences in the perceptions of survival between the four participant groups overall $(\mathrm{p}<0.001)$.

\section{Perceptions of survival if inborn livebirth at 28 weeks' gestation}

Of the 765 livebirths at 28 weeks' gestation, $647(85 \%)$ were born in a tertiary perinatal centre. At one year, 615 (95\%) were alive (615/644 admitted to NICU).

This was the most accurately answered question, with $70 \%$ of respondents estimating survival rates within $10 \%$ of the true rate. There was little variation within each group, apart from a few outliers (Figure 2D). There were no statistically significant differences in the perceptions of survival between the four participant groups overall $(p=0.22)$.

\section{Perceptions of major neurosensory disability in 24-week survivors}

Thirty-three percent of the surviving 24-week infants born in Victoria averaged across three eras (1991-1992, 1997 and 2005) had a major neurosensory disability at two years of corrected age. Outborn and inborn survivors had the same rates of major disability across the three eras.

This article is protected by copyright. All rights reserved 
Most respondents overestimated the risks of major neurosensory disability in outborn and inborn survivors at 24 weeks (Figures $3 \mathrm{~A}$ and 3B). The mean estimate of all four groups combined was $69 \%$ (SD 20.4, 95\% CI 66.4, 71.0) for outborn infants: more than double the true rate of $33 \%$. Only $10 \%$ of respondents estimated the chance of major disability within $10 \%$ of the true rate.

The combined mean estimate of major disability risk for inborn 24-week survivors was $57 \%$ (SD 20.3, 95\% CI 54.3, 58.8). Medical staff from tertiary centres and the PERS/NETS transport team estimated mean chances of major disability of 48\% (SD 19.6) and 47\% (SD 20.2) respectively. Only $15 \%$ of all respondents estimated the chance of major disability within $10 \%$ of the true rate.

There were no differences between the four groups in their perceptions of major disability risk in outborn $(\mathrm{p}=0.84)$ or inborn $(\mathrm{p}=0.64)$ 24-week survivors.

\section{Perceptions of major neurosensory disability in 28-week survivors}

The rate of major neurosensory disability in 28-week survivors born in Victoria averaged across the three eras was $16.5 \%$, one-half that of the 24 -week survivors. Outborn and inborn infants had the same rates of major disability.

Most respondents overestimated the true rate of major neurosensory disability in outborn and inborn survivors at 28 weeks (Figure 4C and 4D). The mean risk estimated by all groups combined was $50 \%$ for outborn survivors and $43 \%$ for inborn survivors. Only $18 \%$ of respondents estimated the chance of major disability for outborn survivors within $10 \%$ of the true rate, whereas $35 \%$ of respondents estimated within $10 \%$ of the true rate for inborn survivors.

There were no statistically significant differences between the four groups in their perceptions of major disability rates in outborn 28 -week survivors $(p=0.63)$, but were for inborn 28-week survivors $(\mathrm{p}<0.001)$.

This article is protected by copyright. All rights reserved 


\section{DISCUSSION}

The aim of our survey was to explore whether perinatal healthcare providers in Victoria had accurate perceptions of outcomes in extremely preterm outborn and inborn infants. We found that despite published Australian population-based outcome data, and similar locally and internationally published studies describing inaccurate estimates, ${ }^{1-5,17-19}$ many practitioners continue to underestimate survival and overestimate major neurosensory disability rates, in both outborn and inborn infants. Although survival and outcome statistics are available from various sources (CCOPMM annual reports, data published in perinatal journals and national perinatal mortality annual reports, local perinatal conferences and preterm infant follow-up study groups), our results indicate availability of these resources does not always translate to accurate knowledge.

Outborn infants were perceived to have much worse prospects for survival compared with their inborn peers. This perception was consistent across all respondent groups. Although extremely preterm outborn infants have higher mortality rates compared with inborns, ${ }^{12}$ perceived risks of mortality were much higher than actual risk. Inborn infants were perceived as having a better chance of surviving; however many participants underestimated their actual survival rates.

Major neurosensory disability rates were overestimated for both outborn and inborn infants, particularly at 24 weeks. Outborn 24 -week survivors were perceived to be at much greater risk of major neurosensory disability compared with their inborn peers. In fact, there were no significant differences in the rates of major neurosensory disability in the 24 or 28 -week outborn and inborn survivors born in Victoria averaged across three eras, 1991-1992, 1997 and 2005 .

These misconceptions regarding infant outcomes have several implications. If an infant is perceived to be at high risk of death or disability, even if inborn, this may alter the management of a woman presenting to a non-tertiary hospital with threatened preterm labour. In the United States, Morse et al. ${ }^{3}$ found that obstetricians who underestimated 
survival were less likely to administer antenatal corticosteroids, perform a caesarean section for fetal distress, or transfer a woman to a perinatal centre before birth. Potentially, some infants who have a good chance of surviving if born in a tertiary centre may not be given that opportunity.

Martinez et al. reported that Australian physicians would frequently limit resuscitation efforts for infants born between 23 and 25 weeks if quality of life chances were perceived to be poor. ${ }^{6}$ Parents may base their decisions regarding non-initiation or limiting of resuscitation efforts based on the risks of death or severe disability presented to them before their infant's birth. This survey has identified that the risks presented may not always be accurate.

Of the small number of non-tertiary GPs and obstetricians who responded to our survey, many did not have accurate perceptions of outcomes of outborn or inborn infants. This was not surprising given the limited experience this group had caring for extremely preterm infants. As more than sixty percent of these clinicians practiced in Level 1 hospitals without a paediatrician onsite, these clinicians would typically seek advice from a PERS or NETS consultant regarding management of threatened preterm labour and survival chances, should in-utero transfer be deemed unsafe or birth imminent. We also hypothesised that these practitioners may have underestimated outborn survival rates because of the emphasis placed on the importance of birth occurring in a perinatal centre to improve survival prospects. However, it was concerning that this small sample of clinicians also perceived inborn infants to have very poor outcomes. Potentially, a pregnant woman may elect not to be transferred if her obstetrician advised that her infant had a low chance of surviving and a high chance of a major disability, even if inborn.

The wide variation in estimates of survival chances by PERS/NETS and tertiary centre medical staff was unexpected. PERS and NETS consultants are frequently asked to provide estimates of survival chances for extremely preterm births by non-tertiary clinicians. In tertiary perinatal centres, neonatologists are largely responsible for counselling families

This article is protected by copyright. All rights reserved 
regarding decision-making around resuscitation and the provision of neonatal intensive care for infants born extremely preterm. However one third of tertiary medical respondents were junior staff, and of these, $57 \%$ had less than one year of NICU experience. This may have affected their ability to accurately estimate outcome. Furthermore, in the year prior to the survey being undertaken, all 12 outborn 24-week infants admitted to a tertiary NICU in Victoria died within 28 days of birth. It was possible that junior medical staff were reflecting on their experiences from that year when responding to our survey.

The estimates of risk of major neurosensory disability for outborn and inborn infants were somewhat surprising. Outcome data have been published for extremely preterm children born in New South Wales and the Australian Capital Territory ${ }^{20}$ and Victoria ${ }^{13,21}$ for more than 25 years. In 2010, Doyle et al. reported that $20 \%$ of 22-27 week survivors born in Victoria in 2005 who were assessed had a major disability. ${ }^{15}$ Given the wealth of local outcome data for these children, it was unclear why survey respondents had such inaccurate perceptions of neurosensory outcome for these children. Translating results of research into clinical practice is clearly sub-optimal.

Our results highlight the need for a readily available tool that healthcare providers can access to calculate survival chances for individual infants based on perinatal risk factors. In the absence of such a resource, we are developing a "preterm birth outcome predictor" to guide decision-making for preterm births in Australia, and plan to make this tool freely available to clinicians.

\section{Strengths and limitations}

This survey was unique in that it was the first to explore and compare perceptions of outcome by medical and nursing staff from tertiary and non-tertiary hospitals and from the perinatal/ neonatal emergency services in Victoria. Although many such medical and nursing staff may not be the woman's primary health care provider, they are in a position to 
influence decision-making as they are often asked for their opinion, or may offer it anyway, even if not asked.

Our aim was to survey a wide range of perinatal healthcare providers. The poor response rate from non-tertiary obstetricians was disappointing; given these clinicians play a key role in decision-making regarding management of preterm labour in a non-tertiary hospital. Given the small number of respondents, we do not suggest the views expressed in this study are representative of all non-tertiary obstetric staff.

It became evident that neurosensory outcome data for 28 -week infants were not as readily available as they were for less mature infants. Many population-based studies in Australia and in comparable European and North American countries follow up 22-27 week infants. ${ }^{15,}{ }^{22-24}$ In retrospect, it would have been prudent to ask participants about their perceptions of survival and major neurosensory disability rates in 27-week infants, instead of 28-week infants.

The questions regarding the chance of major neurosensory disability did not include deafness, which occurs in 1-2\% of extremely preterm survivors. ${ }^{15,16,25}$ Of the 3 children born at 24 weeks' gestation and the one child born at 28 weeks with deafness at two years, 2 had severe developmental delay and were identified as having a major neurosensory disability, whereas the other 2, both born at 24 weeks, did not. Adding the two deaf children otherwise not identified as having a major neurosensory disability at 24 weeks would have little effect on the true average rate of disability, and hence the conclusion that clinicians mostly overestimated the rate of disability at 24 weeks would be unaltered. We acknowledge that omission of deafness was an oversight. Furthermore, if our definitions of "major neurosensory disability" had included more specific standard terms such as moderate or severe cerebral palsy or developmental delay (test scores <-2 SD), rather than problems with walking or thinking, then clinical estimations of major disability may have been different.

This article is protected by copyright. All rights reserved 


\section{CONCLUSION}

This survey found that many perinatal healthcare providers had inaccurate perceptions of outcomes for infants born at 24 or 28 weeks' gestation. The question: "What are we telling the parents of extremely preterm babies?" remains as yet, unanswered.

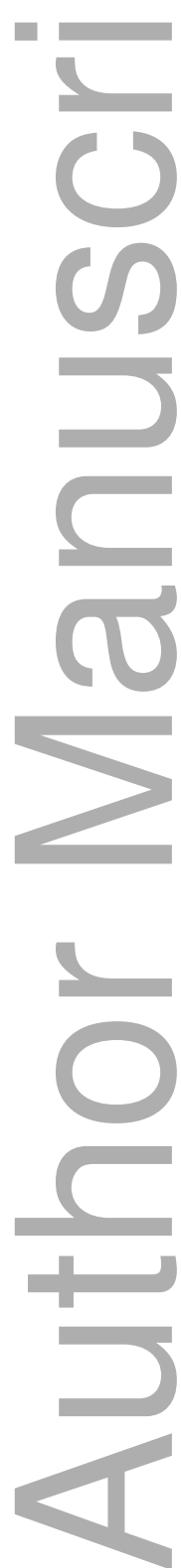

This article is protected by copyright. All rights reserved 


\section{References}

1. Gooi A, Oei J, Lui K. Attitudes of Level II obstetricians towards the care of the extremely premature infant: A national survey. J Paediatr Child Health. 2003;39(6):451-5.

2. Mulvey S, Partridge JC, Martinez AM., et al. The management of extremely premature infants and the perceptions of viability and parental counselling practices of Australian obstetricians. Aust NZ J Obstet Gynaecol. 2001;41(3):269-73.

3. Morse SB, Haywood JL, Goldenberg RL., et al. Estimation of neonatal outcome and perinatal therapy use. Pediatrics. 2000;105(5):1046-50.

4. Blanco F, Suresh G, Howard D, Soll RF. Ensuring accurate knowledge of prematurity outcomes for prenatal counseling. Pediatrics. 2005;115(4):e478-87.

5. Khan R, Burgoyne L, O'Connell M, Dempsey E. Resuscitation at the limits of viability: an Irish perspective. Acta Pædiatr. 2009;98(9):1456-60.

6. Martinez AM, Partridge JC, Yu V., et al. Physician counselling practices and decision-making for extremely preterm infants in the Pacific Rim. J Paediatr Child Health. 2005;41(4):209-14.

7. Marlow N. The elephant in the delivery room. NEJM. 2015;372(19):1856-7.

8. Marlow N. Keeping up with outcomes for infants born at extremely low gestational ages. JAMAPediatr. 2015;169(3):207-8.

9. Rysavy MA, Li L, Bell EF, Das A et al. Between-hospital variation in treatment and outcomes in extremely preterm infants. NEJM. 2015;372(19):1801-11.

This article is protected by copyright. All rights reserved 
10. Cummings J, Committee on Fetus and Newborn. Antenatal counseling regarding resuscitation and intensive care before 25 weeks of gestation. Pediatrics. 2015;136(3):588595.

11. Lasswell SM, Barfield WD, Rochat RW, Blackmon L. Perinatal regionalization for very low-birth-weight and very preterm infants: A Meta-analysis. JAMA. 2010;304(9):9921000 .

12. Boland RA, Dawson JA, Davis PG, Doyle LW. Why birthplace still matters for infants born before 32 weeks: Infant mortality associated with birth at 22-31 weeks' gestation in non-tertiary hospitals in Victoria over two decades. Aust N Z J Obstet Gynaecol. 2015;55(2):163-9.

13. The Victorian Infant Collaboration Study Group. Changing outcome for infants of birth-weight 500-999g born outside of level 3 centres in Victoria. Aust NZ J Obstet Gynaecol. 1997;37(3):253-7.

14. Boland RA, Davis PG, Dawson JA, Doyle LW. Mortality and serious morbidity rates for outborn compared with inborn 22-27 week infants. Perinatal Society of Australia and New Zealand $19^{\text {th }}$ Annual Congress; 22 April 2015; Melbourne, J Paediatr Child Health. 2015; 51(Supplement 1):1-138. Abstract A249, p.83.

15. Doyle LW, Roberts G, Anderson PJ. Outcomes at age 2 years of infants < 28 weeks' gestational age born in Victoria in 2005. J Pediatr. 2010;156(1):49-53.

16. Doyle LW, Roberts G, Anderson PJ, For the Victorian Infant Collaborative Study Group. Changing long-term outcomes for infants 500-999 g birth weight in Victoria, 19792005. Arch Dis Child Fetal Neonatal Ed. 2011;96(6):F443-F7.

This article is protected by copyright. All rights reserved 
17. Duffy D, Reynolds P. Babies born at the threshold of viability: attitudes of paediatric consultants and trainees in South East England. Acta Pædiatr. 2011;100(1):42-6.

18. Kollée L, Cuttini M, Delmas D., et al. Obstetric interventions for babies born before 28 weeks of gestation in Europe: results of the MOSAIC study. BJOG. 2009;116(11):148191. -

19. Lavin JP, Jr, Kantak A, Ohlinger J., et al. Attitudes of obstetric and pediatric health care providers toward resuscitation of infants who are born at the margins of viability. Pediatrics. 2006;118(Supplement 2):S169-76.

20. Lui K, Abdel-Latif ME, Allgood CL., et al. Improved outcomes of extremely premature outborn infants: Effects of strategic changes in perinatal and retrieval services. Pediatrics. 2006;118(5):2076-83.

21. Kitchen WH, Ford GW, Orgill A., et al. Outcome of extremely low birth weight infants in relation to hospital of birth. Aust N Z J Obstet Gynaecol. 1984;24(1):1-5.

22. Doyle LW, for the Victorian Infant Collaborative Study Group. Outcome at 5 years of age of children 23 to 27 Weeks' gestation: Refining the prognosis.Pediatrics.2001;108 (1):134-41.

23. The EXPRESS Group. One-year survival of extremely preterm infants after active perinatal care in Sweden. JAMA. 2009;301(21):2225-33.

24. Costeloe KL, Hennessy EM, Haider S., et al. Short term outcomes after extreme preterm birth in England: comparison of two birth cohorts in 1995 and 2006 (the EPICure studies). BMJ. 2012;345:e7976.

This article is protected by copyright. All rights reserved 
25. Leversen KT, Sommerfelt K, Rønnestad A., et al. Predicting neurosensory disabilities at two years of age in a national cohort of extremely premature infants. Early Hum Dev. 2010;86(9):581-6.

\section{Figure legends}

\section{Legends for Figures}

Figure 1. Perceptions of survival rates if liveborn at 24 weeks' gestation

The horizontal line in each box is the median. The margins of each box plot represent the 25 th and 75 th centiles. The ends of the whiskers are the 5th and 95th centiles. Solid dots represent outliers. The dashed lines are the true survival rates of 24 -week outborn (37\%, Figure 1A) and inborn (64\%, Figure 1B) livebirths in Victoria in 2001-2009.

\section{Figure 2. Perceptions of survival rates if liveborn at 28 weeks' gestation} The horizontal line in each box is the median. The margins of each box plot represent the $25^{\text {th }}$ and $75^{\text {th }}$ centiles. The ends of the whiskers are the $5^{\text {th }}$ and $95^{\text {th }}$ centiles. Solid dots represent outliers. The dashed lines are the true survival rates of 28 -week outborn (96\%, Figure 2C) and inborn (95\%, Figure 2D) livebirths in Victoria in 2001-2009.

\section{Figure 3. Perceptions of major neurosensory disability rates in 24-week survivors}

The horizontal line in each box is the median. The margins of each box plot represent the 25 th and 75 th centiles. The ends of the whiskers are the 5th and 95th centiles. Solid dots represent outliers. The dashed lines are the true disability rates of outborn (33\%, Figure $3 \mathrm{~A})$ and inborn 24-week survivors (33\%, Figure 3B), born in Victoria averaged across three eras: 1991-1992, 1997 and 2005.

\section{Figure 4. Perceptions of major neurosensory disability rates in 28-week survivors}

This article is protected by copyright. All rights reserved 
The horizontal line in each box is the median. The margins of each box plot represent the 25 th and 75th centiles. The ends of the whiskers are the 5th and 95th centiles. The dashed lines are the true disability rates of outborn (16.5\%, Figure 4C) and inborn 28-week survivors (16.5\%, Figure 4D), born in Victoria averaged across three eras: 1991-1992, 1997 and 2005 .

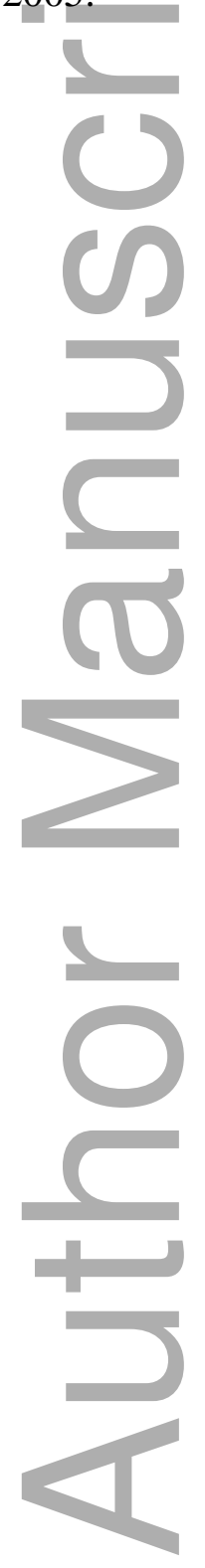

This article is protected by copyright. All rights reserved 
Table 1: Response rates by participant group and workplace

\begin{tabular}{|c|c|c|c|c|}
\hline \multicolumn{3}{|c|}{ Survey participants by workplace and professional group } & \multirow{2}{*}{$\begin{array}{c}\text { Number } \\
\text { surveyed } \\
n=\end{array}$} & \multirow{2}{*}{$\begin{array}{c}\text { Response rate } \\
\text { n }(\%)\end{array}$} \\
\hline Workplace & Group name & Group members & & \\
\hline \multirow{2}{*}{$\begin{array}{l}\text { Non-tertiary maternity } \\
\text { hospitals with Level } 1 \\
\text { or Level } 2 \text { obstetric } \\
\text { and neonatal services } \\
\mathrm{N}=70\end{array}$} & $\begin{array}{l}\text { Non-tertiary } \\
\text { midwives }\end{array}$ & $\begin{array}{l}\text { Midwifery staff } \\
\text { - Midwifery Unit Managers } \\
\text { - Midwifery Educators }\end{array}$ & 109 & $91(83 \%)$ \\
\hline & Obstetricians & $\begin{array}{l}\text { Medical practitioners } \\
\text { - General practitioners (GPs) } \\
\text { - Obstetricians } \\
\text { - GP Obstetricians }\end{array}$ & $650 \dagger$ & $28(4 \%)$ \\
\hline \multirow{2}{*}{$\begin{array}{l}\text { Tertiary perinatal } \\
\text { centre NICUs } \\
\mathrm{N}=3\end{array}$} & $\begin{array}{l}\text { Tertiary } \\
\text { centre }\end{array}$ & $\begin{array}{l}\text { Nursing staff } \\
\text { - Neonatal nurses } \\
\text { - NICU Nurse Educators } \\
\text { - NICU Nurse Unit Managers }\end{array}$ & 278 & $160(58 \%)$ \\
\hline & & $\begin{array}{l}\text { Medical practitioners } \\
\text { - Consultant Neonatologists } \\
\text { - Neonatal Fellows } \\
\text { - Neonatal Registrars }\end{array}$ & 56 & $25(45 \%)$ \\
\hline \multirow{2}{*}{$\begin{array}{l}\text { Perinatal Emergency } \\
\text { Referral Service } \\
\text { (PERS) \& Neonatal } \\
\text { Emergency Transport } \\
\text { Service (NETS) } \\
\mathrm{N}=1\end{array}$} & $\begin{array}{l}\text { Transport } \\
\text { team }\end{array}$ & $\begin{array}{l}\text { Nursing staff } \\
\text { - Neonatal Transport Nurses } \\
\text { - Perinatal Transport Coordinators } \\
\text { - Nurse Educators }\end{array}$ & 30 & $18(60 \%)$ \\
\hline & & $\begin{array}{l}\text { Medical practitioners } \\
\text { - PERS Consultant Obstetricians } \\
\text { - NETS Consultant Neonatologists } \\
\text { - Neonatal Transport Fellows }\end{array}$ & 20 & $16(80 \%)$ \\
\hline TOTAL & & & 1,143 & $339(30 \%)$ \\
\hline
\end{tabular}

†This group-comprised all Royal Australian College of Obstetricians and Gynaecologists (RANZCOG) practitioners, including gynaecologists, who were not eligible to participate.

This article is protected by copyright. All rights reserved 
Table 2: Number of livebirths less than 28 weeks' gestation attended in the past 5 years

\begin{tabular}{|c|c|c|c|c|}
\hline \multicolumn{2}{|c|}{$\begin{array}{l}\text { On how many occasions in the past five years have } \\
\text { you been present at the birth of a preterm infant less } \\
\text { than } 28 \text { weeks' gestation who was resuscitated? }\end{array}$} & $\begin{array}{l}\text { Number of } \\
\text { livebirths } \\
\text { attended } \\
\text { (median) }\end{array}$ & IQR & Range \\
\hline Group name & Group members & & & \\
\hline Non-tertiary midwives & $\begin{array}{l}\text { Midwifery/Nursing staff } \\
\mathrm{n}=91\end{array}$ & 1 & 0,2 & 0 to 10 \\
\hline Obstetricians & $\begin{array}{l}\text { Medical practitioners } \\
\mathrm{n}=28\end{array}$ & 0 & 0,1 & 0 to 5 \\
\hline \multirow[t]{2}{*}{ Tertiary centre } & $\begin{array}{l}\text { Nursing staff } \\
\mathrm{n}=160\end{array}$ & 5 & 0,15 & 0 to 300 \\
\hline & $\begin{array}{l}\text { Medical practitioners } \\
\mathrm{n}=25\end{array}$ & 30 & 15,60 & 0 to 200 \\
\hline \multirow[t]{2}{*}{$\begin{array}{l}\text { Transport Team } \\
\text { (PERS and NETS) }\end{array}$} & $\begin{array}{l}\text { Nursing staff } \\
\mathrm{n}=18\end{array}$ & 3 & 1,20 & 0 to 50 \\
\hline & $\begin{array}{l}\text { Medical practitioners } \\
\mathrm{n}=16\end{array}$ & 38 & 10,50 & 0 to 170 \\
\hline \multicolumn{2}{|l|}{ Combined total } & 3 & $\mathbf{0}, 12$ & o to 300 \\
\hline
\end{tabular}

This article is protected by copyright. All rights reserved 
Perceptions of survival rates if liveborn at 24 weeks' gestation

A: Outborn

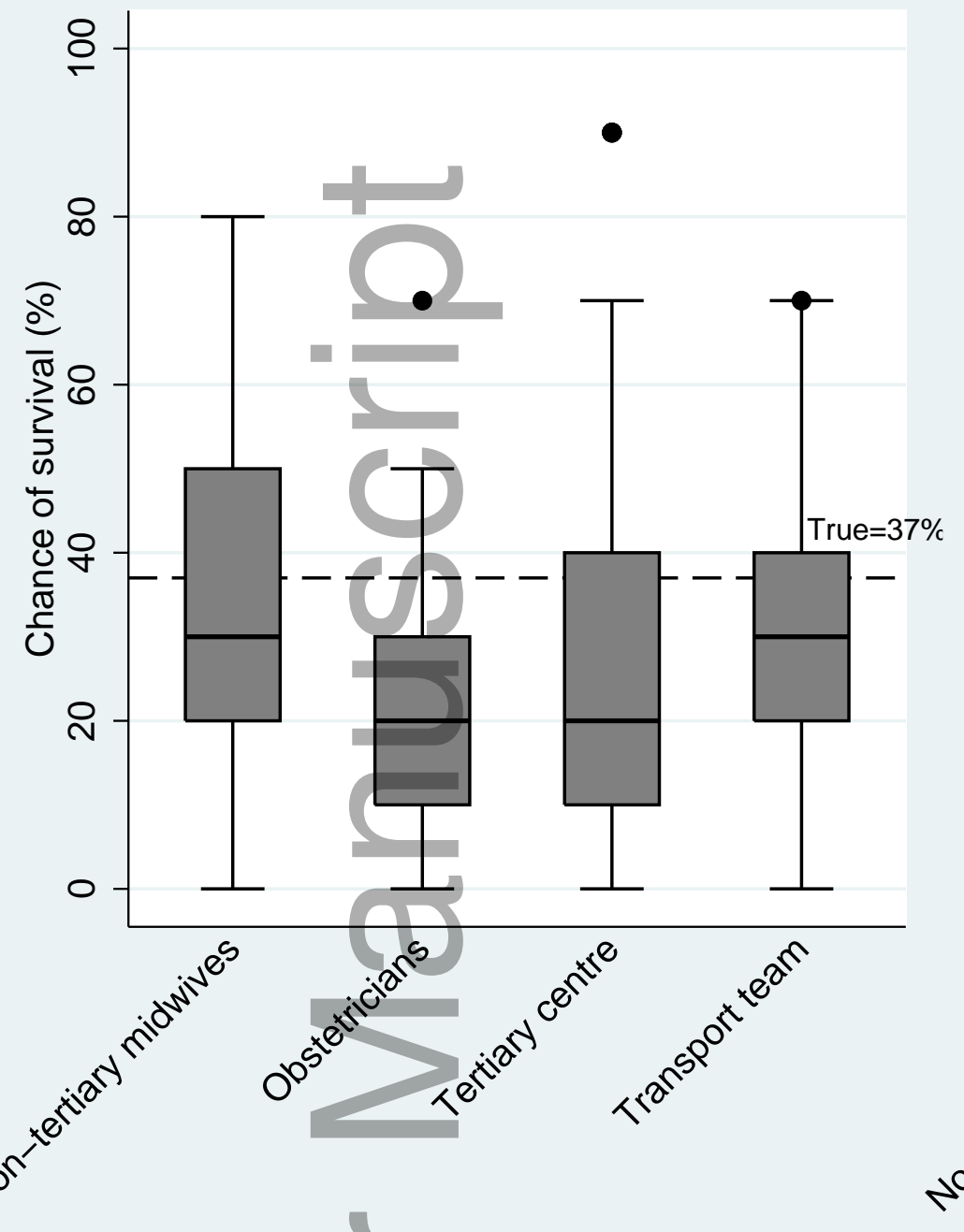

B: Inborn

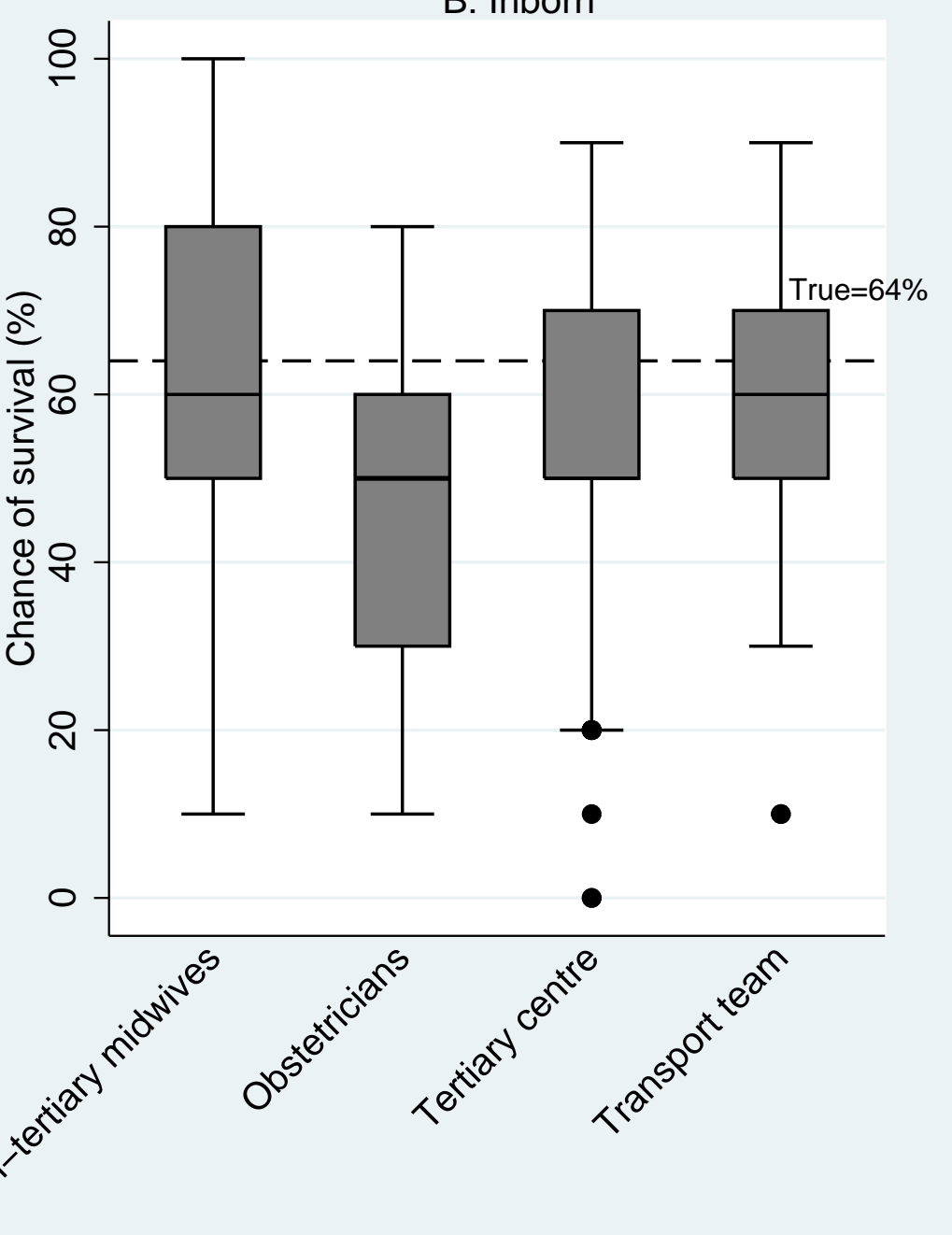

ajo_12448_f1.eps 
Perceptions of survival rates if liveborn at 28 weeks' gestation

C: Outborn

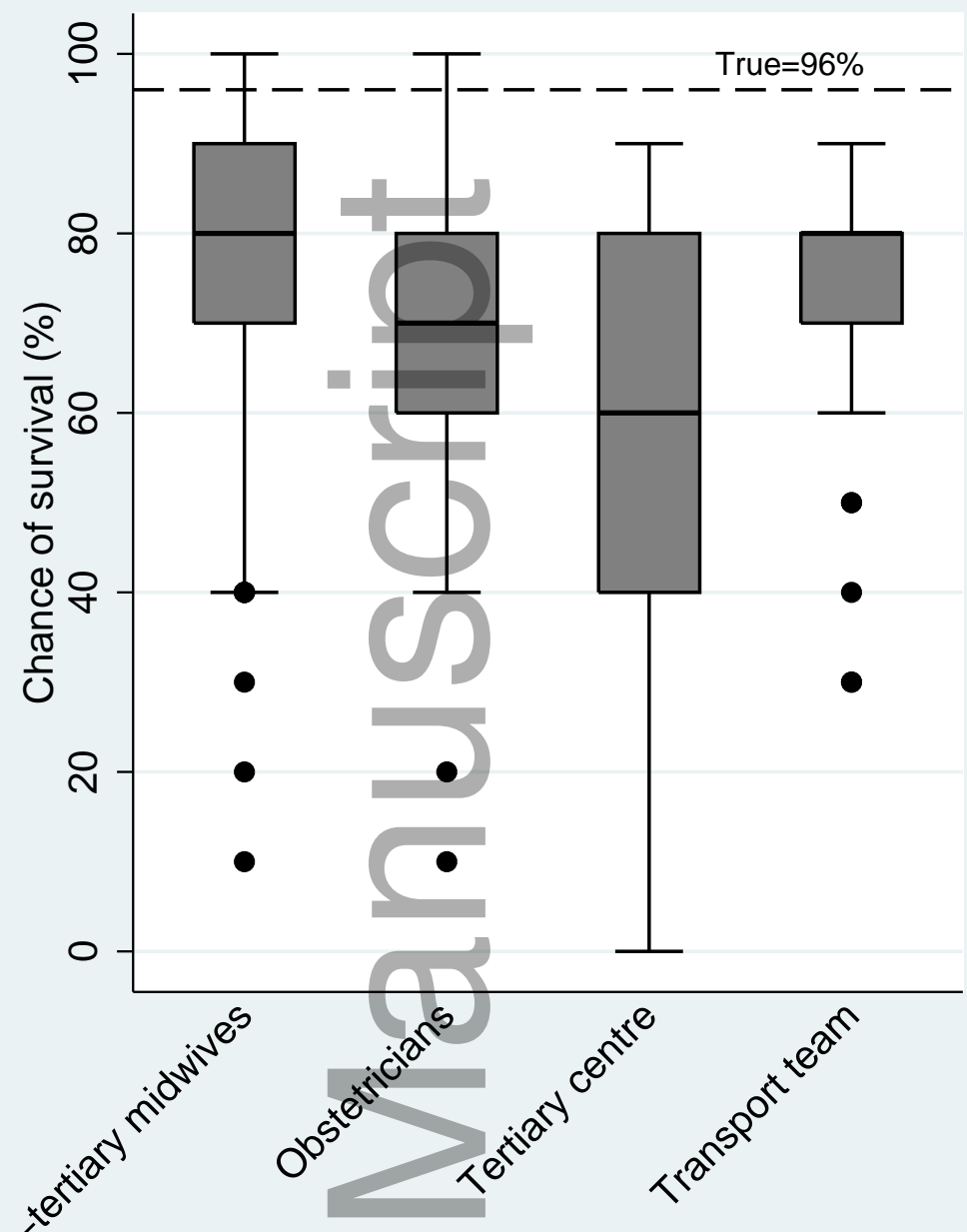

D: Inborn

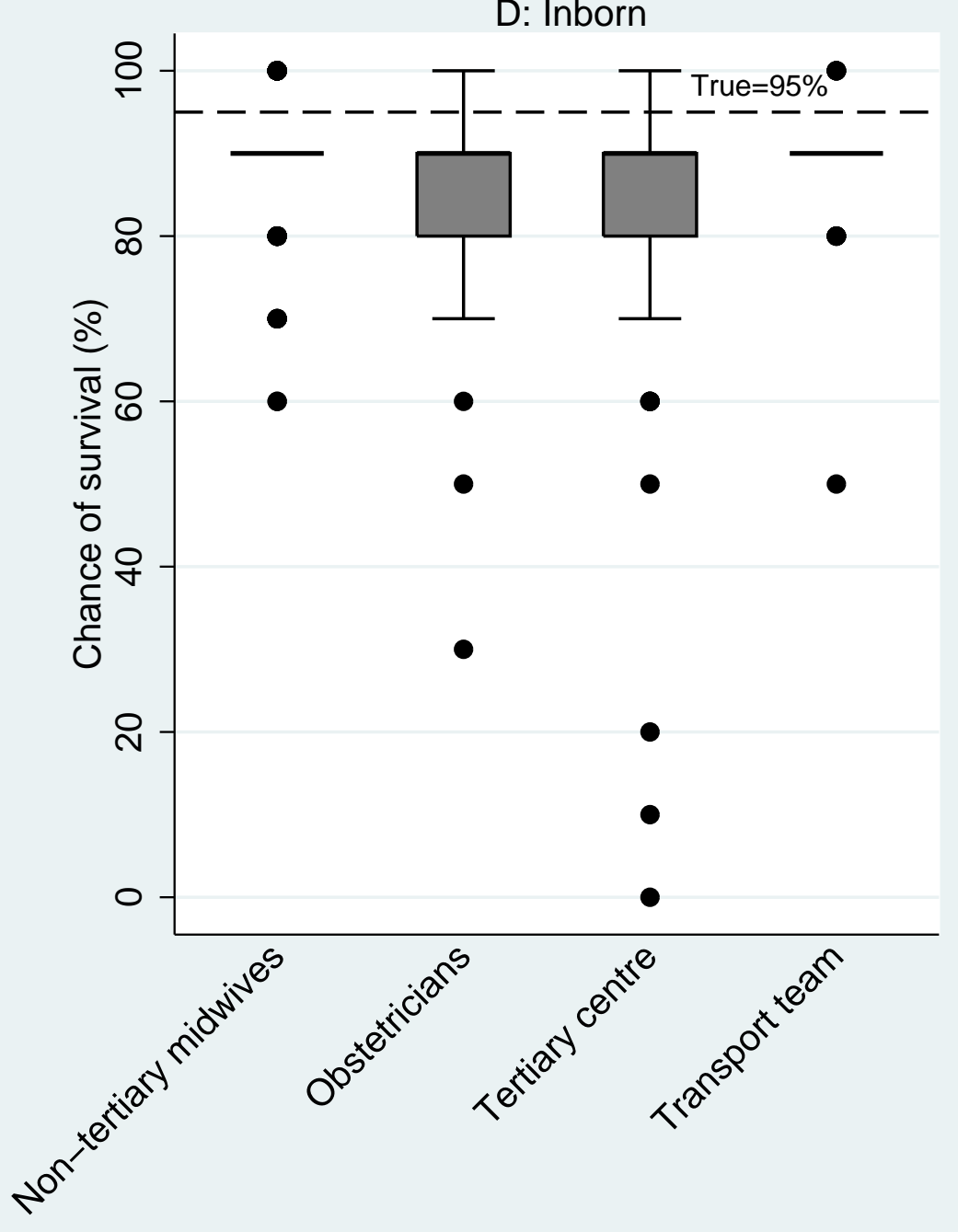

ajo_12448_f2.eps 


\section{Perceptions of major neurosensory disability rates in 24 week survivors}

A: Outborn

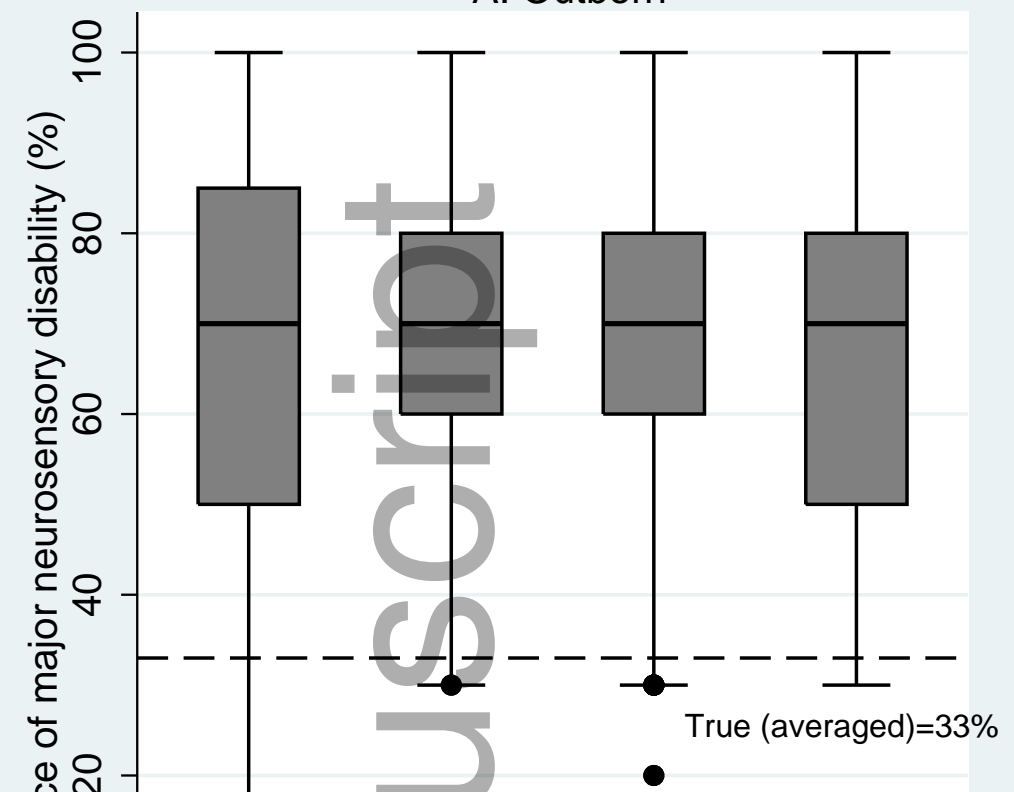

ป

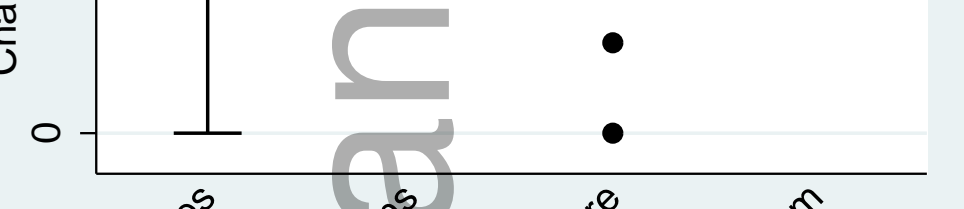

B: Inborn

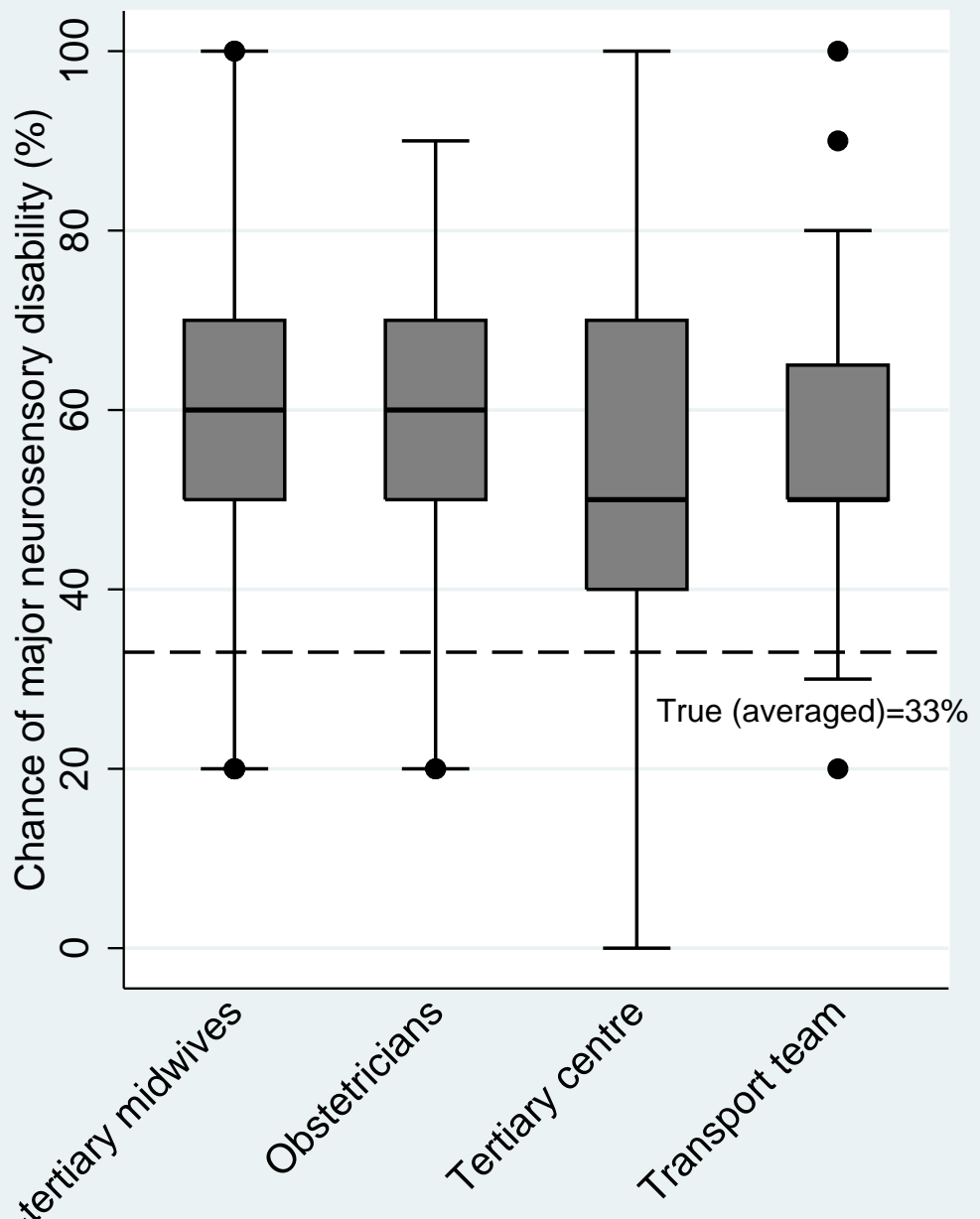

ajo_12448_f3.eps 


\section{Perceptions of major neurosensory disability rates in 28 week survivors}

C: Outborn

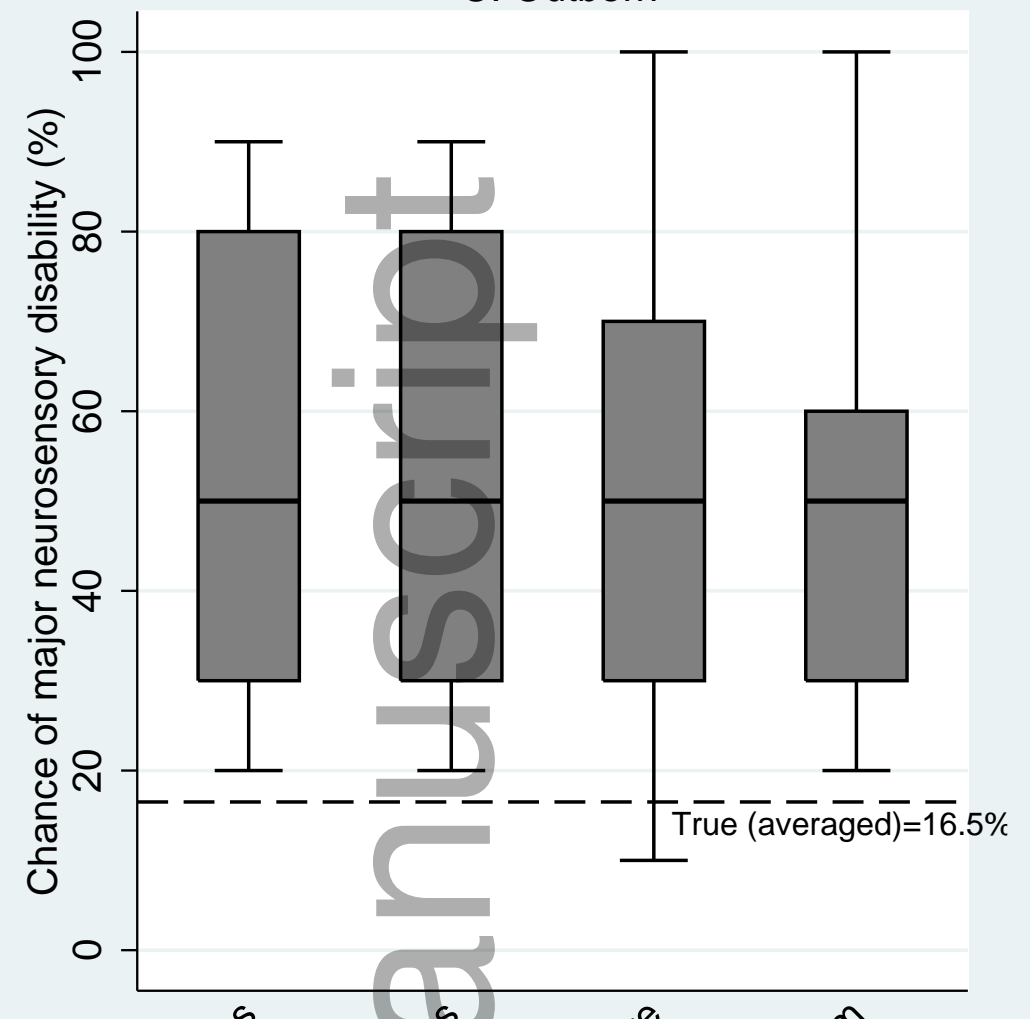

D: Inborn

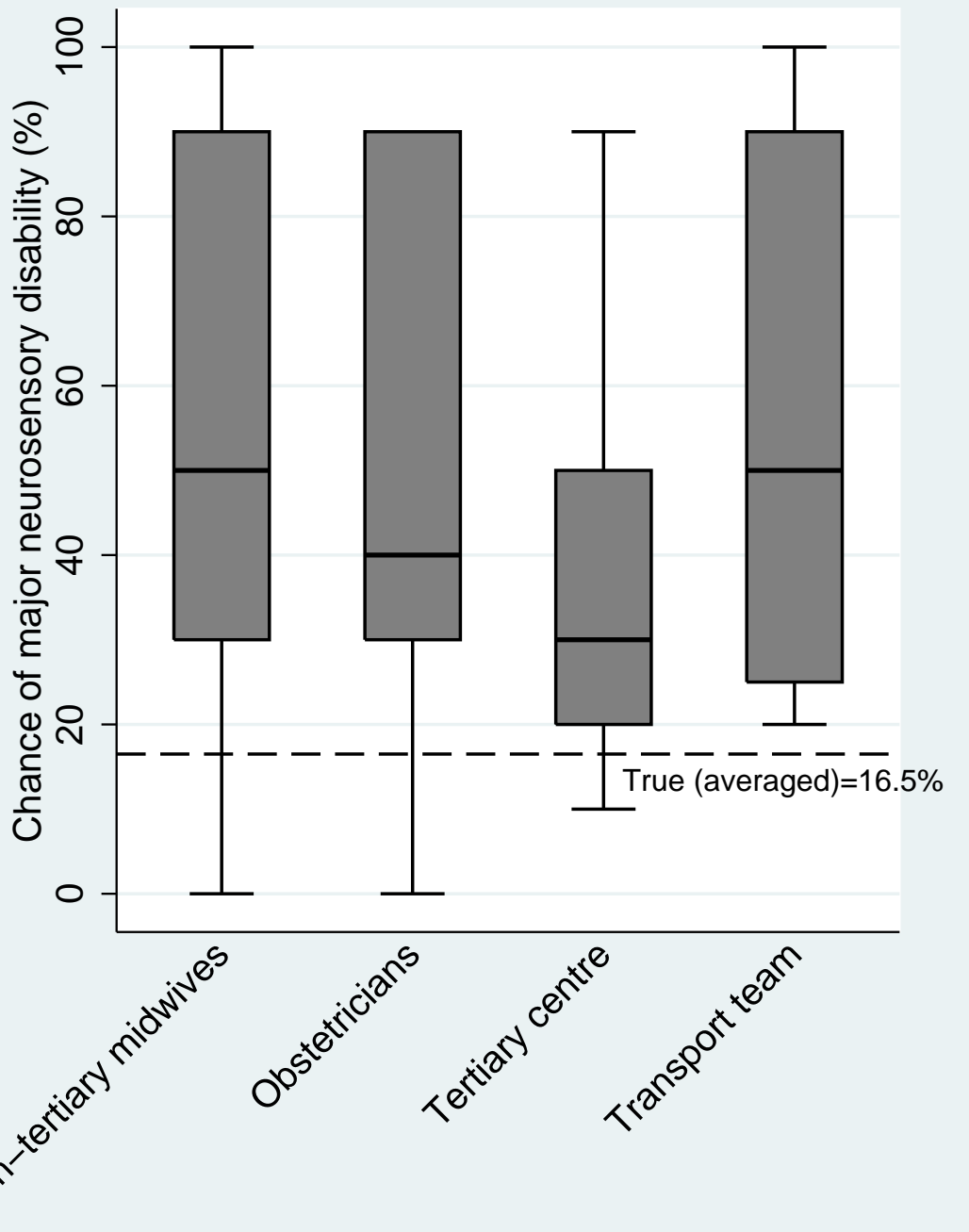

ajo_12448_f4.eps 


\section{University Library}

\section{- M M N E R VA A gateway to Melbourne's research publications}

Minerva Access is the Institutional Repository of The University of Melbourne

Author/s:

Boland, RA;Davis, PG;Dawson, JA;Doyle, LW

Title:

What are we telling the parents of extremely preterm babies?

Date:

2016-06-01

Citation:

Boland, R. A., Davis, P. G., Dawson, J. A. \& Doyle, L. W. (2016). What are we telling the parents of extremely preterm babies?. AUSTRALIAN \& NEW ZEALAND JOURNAL OF OBSTETRICS \& GYNAECOLOGY, 56 (3), pp.274-281. https://doi.org/10.1111/ajo.12448.

Persistent Link:

http://hdl.handle.net/11343/290973 